\title{
Gasification of rice hulls into methane by rumen fluid: A simulation study
}

\author{
John Raymond Barajas $^{1, *}$, Arpon Lucero, Jr. ${ }^{1}$ \\ ${ }^{1}$ Department of Chemical Engineering, Bicol University,Legazpi City, Albay, 4500, Philippines
}

\begin{abstract}
Methane gas, the third widely-used source of energy, has been identified as a potential alternative to climate-change causing fuels. Due to increased climate change awareness, recent trends in researches have shifted their focus on optimizing production rates of methane gas. This study contributes to research by investigating the degree of conversion of rice hulls into methane using rumen fluid. We first identify the kinetic parameters defining therate of hydrolyzing rice hulls into glucose by implementing a semi-factorial experimental design. We then simulated methane production in four different reactor configurations. Historical data were extracted from different literatures and these were subsequently used in the simulation study. Simulation results showed that the continuous stirred tank reactor (CSTR) gave the shortest reaction time and highest methane yield which ranged from $7.1-9.5 \mathrm{~mol} / \mathrm{L}$ and $3-4$ days, respectively. In conclusion, this study provides an alternative approach to the conduct of understanding the optimal conditions necessary to achieve maximal methane gas production.
\end{abstract}

\section{Introduction}

Voluminous carbon emissions due to over dependency on non-renewable energy created a global movement to mandate and increase the use of renewable energy. Philippines, which supports green energy utilization, have continuously encouraged its industries to shift to renewable energy. For example, the implementation of Republic Act 9513 in the country exempts registered businesses from national government income tax if these establishments utilize renewable energy for the first seven years of their commercial operation [1]. As a consequence of this government support, local and foreign investors have prioritized development of renewable energy sources in the country. This shift in stakeholder interest is expected to increase the renewable energy capacity of the Philippines to 15, 304 MW by 2030 [2]. However, despite this present advocacy, the global price of fossil fuels is anticipated to decrease due to competition induced by increased market penetration of renewables [3]. Rather than expanding on renewable sources, the Philippines, as a developing country, is likely to find itself relying heavily on cheap imported coal and oil to supply energy to a large portion of its energy grid [4]. It may be therefore beneficial for industries currently utilizing renewable energy to revert to fossil fuel use to sustain their growth and yearly operations. To address this controversiality arising from renewable energy use, literature suggests that a country aspiring a complete shift to renewables must adapt technologies which have minimal trade-offs and are well-suited to its geographical location, technological capacity, and financial capability [4].

In the present study, we address the gap previously discussed by investigating the possibility of utilizing rice hulls as a nonconventional source of energy. The consumption of rice hulls to produce gaseous fuels (i.e. methane) has been proven to be suitable and

*Corresponding author: jrbarajas12@gmail.com advantageous to rice producing countries [5-7]. The Philippines alone produces about 2 million tons of rice hulls annually [7]. This large quantity of rice residues presents not only an opportunity to mitigate improper disposal but also to promote the use of renewables. To further alleviate issues arising from the economic viability of using renewables, we explore the possibility of using slaughterhouse waste rumen stomachs as essentially free sources of methane producing enzymes. Exploiting the capacity of rumen microbes to induce methanogenesis has been identified as a low-cost alternative to highly expensive methanogens [8]. Leveraging on the potential of these two low-cost alternatives may provide a suitable approach to address concerns related to renewable energy use.

To demonstrate the applicability of the rice hulls and rumen microorganisms in producing methane, we test the extent to which cellulose from rice hulls can be converted into fermentable glucose. Influence of residence time to the glucose yield was assessed through a time-series study. Kinetic models were fitted to the time-series data to describe the behavior of the glucose produced by rumen microbes over time. Consequently, methane production from these microbes were simulated based on the kinetic parameters obtained from the kinetic model which best fitted the time-series data. Furthermore, simulation was also done to identify a reactor configuration that would best suit the methanogenic mechanism being replicated.

\section{Materials and methods}

\subsection{Materials and reagents}

Rice hulls were acquired from a local farm in Sorsogon City, Sorgsogon, Philippines. Rice hulls were oven-dried at $60^{\circ} \mathrm{C}$ overnight to remove excess moisture content. 
After drying, the dried rice hulls were ground into finer particles (average particle size of $100 \mathrm{mesh}$ ). Cellulolytic enzymes used for the conversion of rice hulls into glucose were harvested from waste stomachs (rumen) of cows freshly slaughtered in a local slaughterhouse in the municipality of Daraga, Albay, Philippines. The fluid collected from the waste stomachs were passed through multi-layered sterile cheesecloth. This filtered fluid was then transferred aseptically to a sterile bottle maintained at $39^{\circ} \mathrm{C}$ and flushed with carbon dioxide to ensure the cellulolytic enzyme activity. Sodium hydroxide, hydrochloric acid, dinitrosalicylic acid (DNS), phenol, and sodium sulfite, and Mcdougall's buffer used in this study were all analytical grades and acquired from DKL Laboratory Supplies. Sterile distilled water was used in all experiments.

\subsection{Kinetic study}

Kinetic models that would describe the trend of glucose produced from rumen bacteria were identified from the time-series data we have collected in our previous work [9]. The kinetic parameters that would reflect the rate of glucose production were assessed by fitting the timeseries data into three kinetic models. The linearized form of the zero order, first order, and second order kinetic models are given in Eq. 1, Eq. 2, and Eq. 3, respectively [10].

$$
\begin{gathered}
C_{g}=C_{g 0}-k_{0} t \\
\ln \frac{C_{g 0}}{C_{g}}=k_{1} t \\
\frac{1}{C_{g}}-\frac{1}{C_{g 0}}=k_{2} t
\end{gathered}
$$

where $\mathrm{C}_{\mathrm{g}}$ corresponds to the aqueous concentration of glucose at time $\mathrm{t}(\mathrm{mg} / \mathrm{L}), \mathrm{C}_{\mathrm{go}}$ is the initial aqueous concentration of glucose $(\mathrm{mg} / \mathrm{L}), \mathrm{k}_{0}$ is the kinetic parameter relative to zero order kinetic model, $\mathrm{k}_{1}$ is the kinetic parameter relative to first order kinetic model, $\mathrm{k}_{2}$ is the kinetic parameter relative to the second order kinetic model, and $t$ is time ( $\mathrm{min})$. The kinetic model that gave the highest $\mathrm{R}^{2}$ was chosen as the best fit to the data.

\subsection{Simulation study}

To simulate the production of methane in a chemical reactor, a mathematical approach described in literature was adopted in this study [10]. The methodology of this simulation is summarized in Fig. 1. The reaction mechanism of methane produced from waste biomass substrates was identified based on the metabolic pathways described in literature [11-13]. The working chemical reaction used in this study is given as follows:

$$
\begin{gathered}
\mathrm{C}_{6} \mathrm{H}_{10} \mathrm{O}_{5}+\mathrm{H}_{2} \mathrm{O} \rightarrow \mathrm{C}_{6} \mathrm{H}_{12} \mathrm{O}_{6} \\
\mathrm{C}_{6} \mathrm{H}_{12} \mathrm{O}_{6} \rightarrow 3 \mathrm{CH}_{3} \mathrm{COOH} \\
\mathrm{CH}_{3} \mathrm{COOH} \rightarrow \mathrm{CH}_{4}+\mathrm{CO}_{2}
\end{gathered}
$$

The net rate of reaction for each specie described in the mechanism was determined by defining the rate of reaction relative to each specie using elementary rate laws. The kinetic parameter used for R1 was based on the result of the kinetic study employed in this study. In contrast, the kinetic parameters used for $\mathbf{R} 2$ and $\mathbf{R 3}$ were based on historical data in published literature [11-14]. After establishing a reaction mechanism, mole balances were applied to each of the following reactors: (a) batch; (b) semi-batch; (c) continuous-stirred tank (CSTR); and (d) plug-flow (PFR). Design equations for each reactor were derived from the general mole balance equation given in Eq. 4 [10].

$$
F_{i o}-F_{i}+\int_{0}^{V} r_{i} d V=\frac{d N_{i}}{d t}
$$

where $F_{i o}$ is the rate of flow of specie $i$ into a reactor, $F_{i}$ is the rate of flow of specie $i$ out of a reactor, the integral of $\left(r_{i} \mathrm{dV}\right)$ is the rate of generation of specie $i$ relative to its rate of reaction $\left(r_{i}\right)$ at a given reactor volume $(V)$, and $\left(\mathrm{dN}_{\mathrm{i}}\right) / \mathrm{dt}$ is the rate of accumulation of specie i. All simulations were done on the assumption that each reactor is operating at steady-state conditions.

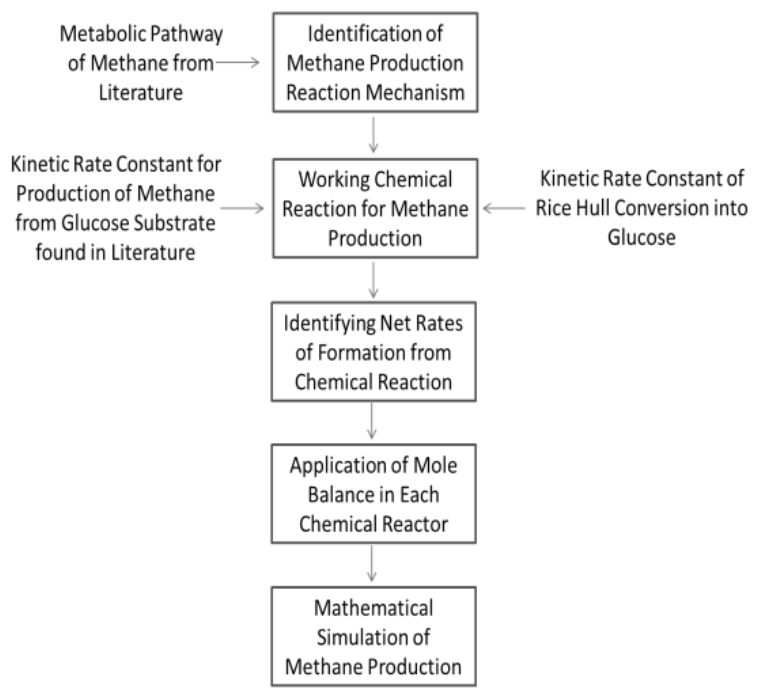

Figure 1. Flow of Simulation Implemented in the Study

\section{Results and discussion}

\subsection{Kinetic study results}

The highest glucose concentration achieved was 0.17 g/L. As shown in Fig. 2, this glucose concentration was attained at $54 \mathrm{~h}$. The rumen fluid hydrolysis was then stopped at this point since glucose in solution starts to significantly decrease beyond $54 \mathrm{~h}$ (data not shown). Due to this observed behavior, the kinetic data was analyzed only up to this point. 


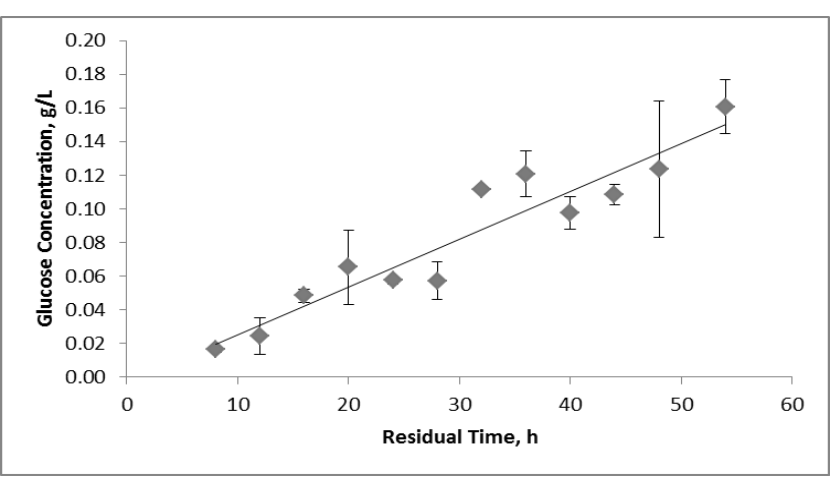

Figure 2. Concentration of Glucose Produced over Time; rumen fluid dosage $1 \%(\mathrm{w} / \mathrm{v})$; rice hull dosage $10 \mathrm{~g} / \mathrm{L}$; temperature $39^{\circ} \mathrm{C}$.

The kinetic data obtained were fitted into three kinetic equations: zero order, first order, and second order equations. As presented in Table 1, the rumen fluid hydrolysis of rice hulls into glucose behaves like a zero order rate equation. This results imply that the increase (or decrease) of glucose concentration in solution is solely a function of time. Hence, the conversion of rice hull into glucose was assumed to be zero order. To be consistent with the assumptions stated in a steady-state operating plug-flow reactor, the conversion of rice hull into glucose was instead assumed to behave like a first order reaction.

Table 1. Kinetic Parameters Obtained

\begin{tabular}{lccc}
\hline \multicolumn{1}{c}{ Kinetic Equation } & Rate Constant, $\mathbf{k}$ & Unit & $\mathbf{R}^{\mathbf{2}}$ \\
\hline Zero Order & 0.0028 & $\mathrm{~g} \mathrm{~L}^{-1} \mathrm{hr}^{-1}$ & 0.8962 \\
First Order & 0.043 & $\mathrm{hr}^{-1}$ & 0.8309 \\
Second Order & 0.93 & $\mathrm{~L} \mathrm{~g}^{-1} \mathrm{hr}^{-1}$ & 0.6361 \\
\hline
\end{tabular}

\subsection{Simulation in a batch reactor}

The first reactor configuration investigated was a batch reactor. Batch reactors are commonly used in almost experiments because of their simplicity. This type of reactor is relatively easy to use because it is operated at constant temperature (isothermal) and constant volume [13]. As an application of a batch reactor, these predominant conditions were applied in the simulations conducted in this experiment.

Results of this simulation are summarized in Figure 3. On a span of 200 days of methane production, a lower feed concentration (e. g. $0.5 \mathrm{~mol} / \mathrm{L}$ ) required a longer time to reach equilibrium and achieve the highest methane yield at this condition. This implied that mass transfer limitations were present in this system. Mass transfer limitations are defined by a lower driving force between the molecules of each interacting reactant. With a lower driving force between each reactant, contact between molecules of the biomass $\left(\mathrm{C}_{6} \mathrm{H}_{10} \mathrm{O}_{5}\right)$ and $\mathrm{H}_{2} \mathrm{O}$ is limited and free molecules of $\mathrm{C}_{6} \mathrm{H}_{10} \mathrm{O}_{5}$ and $\mathrm{H}_{2} \mathrm{O}$ remain unreacted [13].

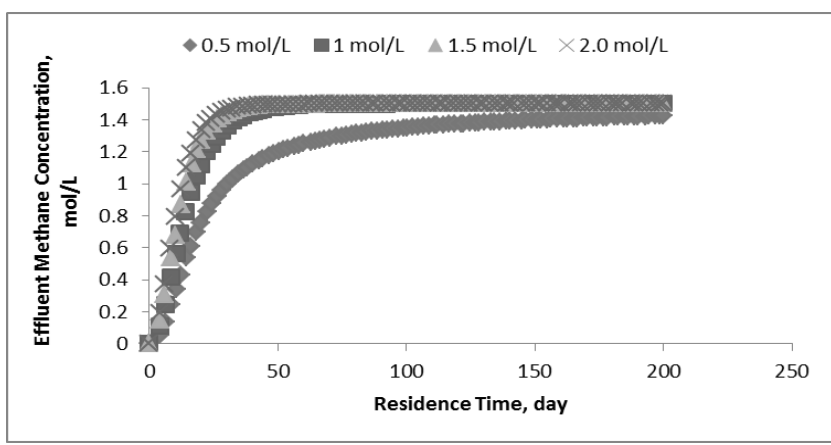

Figure 3. Methane Yield at Different Biomass Concentrations in a Batch Reactor

\subsection{Simulation in a continuous stirred tank reactor}

The second reactor configuration studied was a CSTR. This was considered in this research because it is: (1) reliable; (2) widely used in anaerobic digestion processes; (3) and simple in operation [14]. In contrast to a batch reactor, the time lapsed in flow reactors (e.g. CSTR) is conveniently measure in terms of space time. Space time is defined as the time necessary to process a reactor volume at a given set of initial conditions [13]. Space time is approximately equal to residence time in a batch reactor as long as the conditions of inlet feed in a CSTR are the same conditions in a batch reactor [10]. Hence, the results of simulation in a CSTR can be evaluated the same way a batch reactor was evaluated in this study.

Simulations results for the CSTR configuration are summarized in Figure 4. Results of CSTR simulations were somewhat different with the batch reactor simulations. Although mass transfer limitations were also observed due to a lower driving force between reactants, CSTR configuration reached maximum methane yields faster. However, a decrease in methane yield was observed for longer space time. A maximum methane concentration was observed for all initial $\mathrm{C}_{6} \mathrm{H}_{10} \mathrm{O}_{5}$ feed concentrations. Although the trend in a batch reactor should also be observed in a CSTR, the rapid depletion of $\mathrm{H}_{2} \mathrm{O}$ as $\mathrm{C}_{6} \mathrm{H}_{10} \mathrm{O}_{5}$ initial concentration increases causes the conversion rate of reactants to methane decreases. A sharp decrease in $\mathrm{H}_{2} \mathrm{O}$ indicated the fast conversion rate of the reactants to methane. Oppositely, decrease in $\mathrm{H}_{2} \mathrm{O}$ consumption was observed as space time increases. Although $\mathrm{C}_{6} \mathrm{H}_{10} \mathrm{O}_{5}$ molecules were sufficiently introduced, no adequate amount of free $\mathrm{H}_{2} \mathrm{O}$ molecules was available to react with $\mathrm{C}_{6} \mathrm{H}_{10} \mathrm{O}_{5}$ which finally results to a lower methane yield.

\subsection{Simulation in a plug flow reactor}

The third reactor configuration considered was a PFR. This reactor configuration was chosen on the basis of low initial investment costs, excellent efficiency, and convenient operation and maintenance $[\mathbf{1 0}]$. This reactor is also classified as a flow reactor in which space time can suitably represent residence times in batch reactors. 


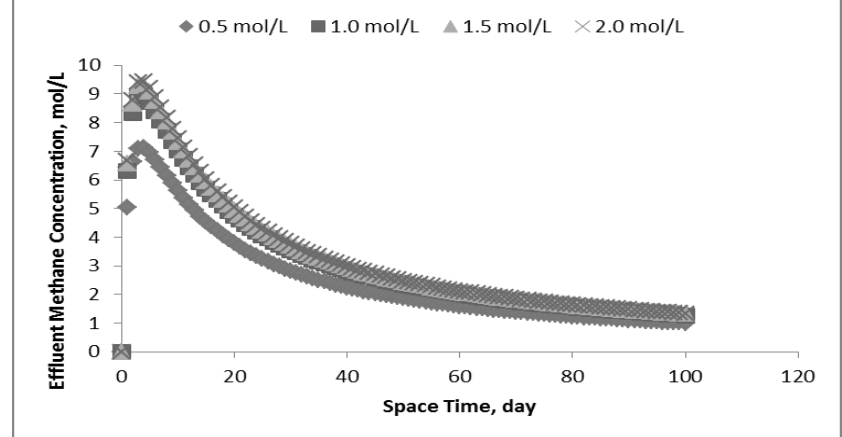

Figure 4. Methane Yield at Different Biomass Concentrations in a Continuous Stirred Tank Reactor

Therefore, PFR simulation results were also assessed the same way in the previous reactors discussed.Simulations results for the PFR configuration are shown in Fig. 5. Results of PFR simulations were almost similar with the batch reactor simulations. Despite a same trend were observed for both PFR and batch reactor simulations, PFR reached faster equilibrium methane yields faster, especially in lower $\mathrm{C}_{6} \mathrm{H}_{10} \mathrm{O}_{5}$ initial concentrations, in comparison with a batch reactor. This implied that a PFR is more suitable and favorable in lower reactant concentrations. This explained by the fact that at every differential distance the reactants travel within a PFR thorough mixing is applied, allowing intimate contact between reactants [13]. Even though the reactions are mass transfer limited at low concentrations, the flow within PFR (which is analogous to how water travels in the stem of a plant and distributed to its part) forces free $\mathrm{H}_{2} \mathrm{O}$ molecules to react with $\mathrm{C}_{6} \mathrm{H}_{10} \mathrm{O}_{5}$ molecules [13].

In comparison with the batch reactor, PFR had slightly higher unreacted $\mathrm{H}_{2} \mathrm{O}$ molecules. Typically, a PFR should have lower unreacted molecules as compared to a batch reactor since it allows intimate contact between reactants [13]. Although this trend is unusual of the PFR configuration [16], it can be hypothesized that the absence of back mixing, which is the dominant characteristic of a batch reactor, actually became a slight disadvantage at higher initial $\mathrm{C}_{6} \mathrm{H}_{10} \mathrm{O}_{5}$ concentrations. Every differential distance in the PFR represents a volume element and since no two (or more) volume elements is exchanged [19], the total free reactant molecules slightly becomes less available within the reactor. Hence, even though an increase in methane yield should be expected [20], this was not observed.

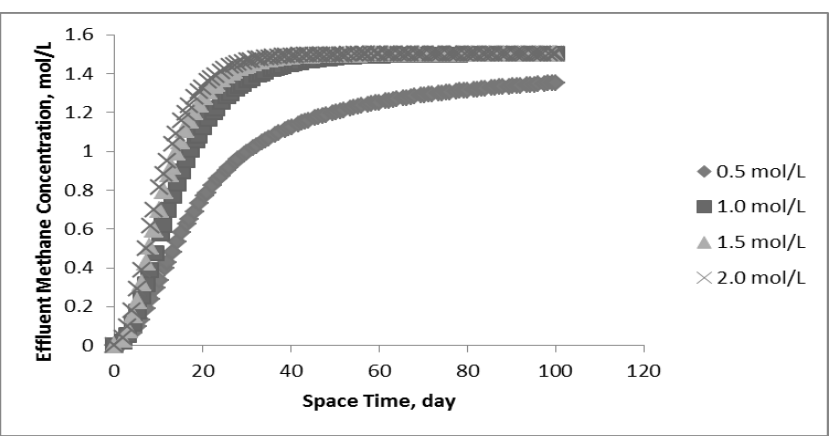

Figure 5. Methane Yield at Different Biomass Concentrations in a Plug Flow Reactor

\subsection{Simulation in a Semi-Batch Reactor}

The last reactor studied was a semi-batch reactor configuration. The semi-batch reactor is defined by a flexible system in which reaction speed is controlled with ease because formation of products proceeds as reactants are carefully added [13]. This configuration was also selected due to the fact that processes optimization is enhanced due to varying reactant dosing [17]. While slowing the reaction speed is not a necessary concern for methane production in anaerobic digestion processes, it was still worthwhile to explore this configuration. Notable findings are discussed in the proceeding paragraphs. For consistency with previous simulations, semi-batch reactor results were also plotted against the residence time and results were analysed in a manner similar to previously discussed outcomes.

Simulation results for the semi-batch reactor are presented in Fig. 6. These results implied that a semibatch reactor configuration is not favourable in methane production. This is attributed to the fact that since reactant is dosed on a daily basis (e. g. $2.5 \mathrm{~L}$ is added per day), inadequate amount of reactant was available to drive the reaction towards methane formation. In comparison with the previous reactors, longer residence times were needed to achieve high methane yields and these indicated a slower breakthrough on mass transfer limitations. It was only through an accumulated amount of reactant on the $60^{\text {th }}$ to the $100^{\text {th }}$ day of operation that mass transfer limitations were evidently overcome. In addition, in spite of the fact that a semi-batch reactor configuration was able to almost complete consume $\mathrm{H}_{2} \mathrm{O}$ molecules; a lower overall methane yield strengthened the claim of this study that a semi-batch reactor configuration is not suitable in methane production.

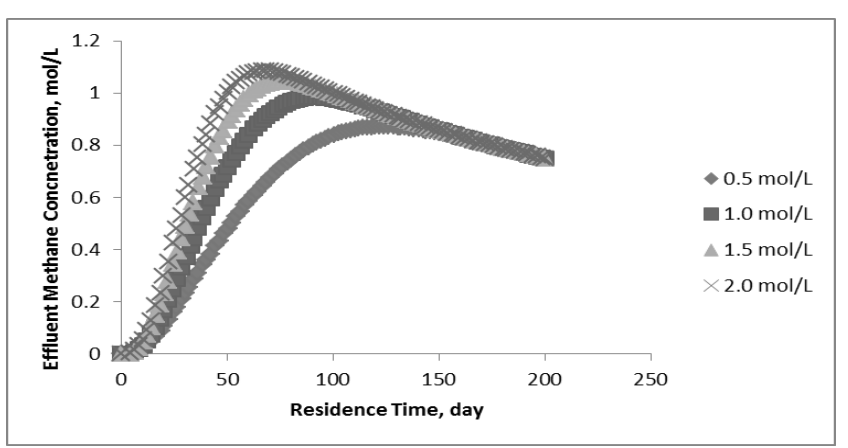

Figure 6. Methane Yield at Different Biomass Concentrations in a Plug Flow Reactor

\section{Conclusion}

It can be concluded that the best reactor configuration for methane production was CSTR. It gave the highest methane yield with a value of $9.45 \mathrm{~mol} / \mathrm{L}$. This presented a huge advantage over other reactor configurations. In addition, a lower reported space time to reach the highest methane yield at the corresponding $\mathrm{C}_{6} \mathrm{H}_{10} \mathrm{O}_{5}$ concentration further supported this claim. However, these results also suggest a huge disadvantage since the highest methane yield can only be achieved on the fourth day. Methane production stability is of great concern for 
long term methane production in CSTR since a rapid decrease is to be expected after the fourth day of production. As solution to this problem, recirculation of feed is expected to cause operational stability and high methane yield at relatively short space times [18]. In addition, reactor performance could be improved through optimization of reactor volume which results to reliable anaerobic digestion [14].

We would like to thank the Chemical Engineering Department of Bicol University College of Engineering for allowing us to use their facilities to complete this study.

\section{References}

[1] Fischer C. and Werge M. EU as a Recycling Available online at https://www.doe.gov.ph/sites/default/files/pdf/iss uances/20081216-ra-09513-gma.pdf

[2] Brahim S. P. Renewable energy and energy security in the Philippines, Energy Procedia 52, 2014, 480-486.

[3] Foster E., Contestabile M., Blazquez J., Manzano B., Workman M., and Shah N. The unstudied barriers to widespread renewable energy development: Fossil fuel price responses, Energy Policy 103, 2017, 258-264.

[4] Pfenniger S., and Keirstead J. Renewables, nuclear or fossil fuels? Scenarios for Great Britain's power system considering costs, emission and energy security, Applied Energy $152,2015,83-93$.

[5] Ismail O., Urbanus M., Murage H., and Francis O. Conversion of rice husk into an energy source through gasification technology, International Journal of Science and Research 5(9), 2016, 1264-1268.

[6] Chungsangunsit T., Gheewala S.H., and Patumsawad S. Environmental assessment of electricity production from rice husk: A case study in Thailand, Electrical Supply Industry in Transition:Issues and Prospect for Asia, 2004, 20-59.

[7] Fung V.W.H. Biomass power development for the Philippines, Agricultural Engineering International: the CIGR Journal of Scientific Research and Development, 2003, 1-23.

[8] Christopherson M. R., and Suen G. "Nature's bioreactorthe rumen as a model for biofuel production," Biofuels 4 (5), 2013, 511-521.

[9] Maglipon K., Madridano K., Araojo J., and Barajas J.R. Alcoholic fermentation of rice hulls hydrolyzed by rumen fluid obtained from slaughterhouse wastes, Systems and Information Engineering Design Symposium SIEDS, 2017, 16-19.

[10]Fogler S.H. Elements of chemical reaction engineering, $4^{\text {th }}$ ed. Pearson Education Inc., 2005.

[11] Kondusamy D., and Kalamdhad A.S. Pretreatment and anaerobic digestion of food waste for high rate methane production - A review,
Journal of Environmental Chemical Engineering 2, 2014, 1821-1830.

[12] Kothari R., Pandey A.K., Kumar S., Tyagi V.V., and Tyagi S.K. Different aspects of dry anaerobic digestion for bio-energy: An overview, Renewable and Sustainable Energy Reviews 39, 2014, 174-195.

[13] Levenspiel O. Chemical Reaction Engineering, 3rd ed., New York, USA: John Wiley and Sons, 1999.

[14] Mao C., Feng Y., Wang X., and Ren G. 'Review on research achievements of biogas from anaerobic digestion', Renewable and Sustainable Energy Reviews 45, 2015, 540-555.

[15] Sharma V., Testa C., Lastella G., Cornacchia G., and Comparato M. 'Inclined-plug-flow type reactor for anaerobic digestion of semi-solid waste', Applied Energy 65(1-4), 2000, 173-185.

[16] Available online at http://sistemas.eel.usp.br/docentes/arquivos/5817 712/326/IntroductionReactor.pdf

[17] Hvala N., Aller F., Miteva T., and Kukanja D. Modelling simulation and control of an industrial, semi-batch, emulsion-polymerization reactor', Computers \& Chemical Engineering35(10), 2011, 2066-2080.

[18] PengX., Nges I.A., and Liu J. "Improving methane production from wheat straw by digestate liquor recirculation in continuous stirred tank processes," Renewable Energy 85, 2016, 12 18.

[19] Available online at http://jbrwww.che.wisc.edu/home/jbraw/chemrea cfun/ch8/slides-mixing.pdf

[20] Available online at http://www.essentialchemicalindustry.org/proces ses/chemical-reactors.html 